\title{
Estimasi Parameter Distribusi Weibull dan Aplikasinya Pada Pengendalian Mutu Dengan Memanfaatkan Kuantil
}

\author{
Cecilia Novianti Salsinha ${ }^{1}$ \\ ${ }^{1}$ Universitas Timor, ceciliasalsinha@unimor.ac.id
}

\begin{abstract}
Weibull distribution is one of the continuous probability distributions. As the other distributions, Weibull distribution is also characterized by Mean, Variance and Moment Generation Function. The advantage of this distribution compared to other distributions is its flexibility, that is, this distribution can change to another distribution such as an exponential distribution depending on the value of the selected distribution parameters, namely scale parameters and form parameters. From the distribution graph, it can be shown that, the flexibility will appear very clear. One application of the Weibull distribution is in statistical process control. Because not all data is normally distributed, the Shewhart control chart cannot be used. One way to solve this problem is that the data is analyzed with Weibull control charts by utilizing quantiles, namely $0.00135,0.5$ and 0.99865 . Quantile 0.00135 is the bottom quintile used to form the Lower Control Limit, the Middle Line is the median of the data, which is 0.5 which replaces the average and the last to form the Upper Control Limit the top quintile is 0.99865 . By generating 200 data with Weibull distribution, if the data is analyzed by Shewhart control charts then there is a lot of data that is outside the control limit so it will be concluded that the graph is out of control. Therefore, if the data is not from a Normal distribution, the use of Shewhart control charts is not recommended.
\end{abstract}

Keywords: Weibull Distribution, Maximum Likelihood Estimation (MLE), Quality Control, Weibull Control Charts

\begin{abstract}
Abstrak. Distribusi Weibull merupakan salah satu distribusi probabilitas kontinu. Sama halnya dengan distribusi lainnya, distribusi Weibull pun dicirikan dengan Mean, Variansi dan Fungsi Pembangkit Momen. Kelebihan distribusi ini dibandingkan dengan distribusi lainnya adalah fleksibilitasnya, yaitu distribusi ini dapat berubah menjadi distribusi lain seperti distribusi eksponensial tergantung pada nilai parameter distribusi yang dipilih yaitu parameter skala dan parameter bentuk. Jika dilihat dari grafik distribusinya maka akan tampak sangat jelas fleksibilitas tersebut. Salah satu aplikasi dari distribusi Weibull yaitu dalam pengendalian proses statistik. Oleh karena tidak semua data berdistribusi normal maka grafik pengendali Shewhart tidak dapat digunakan. Salah satu cara menyelesaikan masalah tersebut adalah data dianalisis dengan grafik pengendali Weibull dengan memanfaatkan kuantil-kuantil yaitu 0,00135, 0,5 dan 0,99865. Kuantil 0,00135 adalah kuantil bawah yang digunakan untuk membentuk Batas Pengendali Bawah, Garis Tengah adalah median dari data yaitu 0,5 yang menggantikan rata-rata dan untuk membentuk Batas Pengendali Atas digunakan kuantil atas yaitu 0,99865. Dengan membangkitkan data sebanyak 200 data berdistribusi Weibull, jika data tersebut dianalisis dengan grafik pengendali Shewhart maka terdapat banyak data yang berada diluar batas pengendali sehingga akan disimpulkan bahwa grafik tak terkendali. Oleh karena itu, jika data bukan berasal dari distribusi Normal, penggunaan grafik pengendali Shewhart tidak disarankan.
\end{abstract}

Kata Kunci: Distribusi Weibull, Estimasi Maximum Likelihood, Pengendalian Mutu, Grafik Pengendali Weibull 


\section{Pendahuluan}

Secara umum fungsi densitas dari distribusi Weibull adalah

$$
f(x)= \begin{cases}\alpha \beta x^{\beta-1} e^{-\alpha x^{\beta}}, & \text { untuk } x>0, \alpha>0, \beta>0 \\ 0, & \text { selainnya }\end{cases}
$$

dimana $\alpha$ adalah parameter skala dan $\beta$ adalah parameter bentuk dari distribusi Weibull. Sama halnya dengan mencari parameter pada distibusi lainnya seperti Distribusi Normal, parameter $\alpha$ dan $\beta$ juga dapat diperoleh dengan memanfaatkan metode Maximum Likelihood Estimation (MLE). Namun proses memperoleh nilai parameternya tidak semudah Distribusi Normal. Dibutuhkan bantuan software seperti Minitab untuk memperolehnya.

Distribusi Weibull banyak diaplikasikan pada Pengendalian Mutu (Quality Kontrol) terutama untuk data waktu hidup (lifetime data). Salah satu alat yang digunakan dalam pengendalian mutu adalah grafik pengendali (control charts). Grafik pengendali adalah perangkat statistik grafis yang digunakan untuk mengontrol suatu proses berulang. Grafik pengendali sangat berguna dalam menetapkan standar pencapaian dari sebuah proses, membantu mencapai standar tersebut dan mempertimbangkan standar mana yang sudah tercapai. Grafik pengendali yang biasanya digunakan dalam praktik didasarkan pada analisis distribusi normal yaitu dengan rata-rata Shewhart dan kisaran grafik pengendali $3 \sigma$ (standar deviasi). Namun demikian tidak semua data berdistribusi normal. Jika data tak berdistribusi normal dan tetap dianalisis dengan grafik pengendali tersebut dengan mengasumsikan bahwa data berdistribusi normal maka error yang besar akan terjadi [1]. Oleh karena itu akan dibahas mengenai grafik pengendali berdasrkan data yang berdistribusi Weibull dengan memanfaatkan kuantil-kuantil yaitu 0,00135, 0,5 dan 0,99865 yang akan digunakan sebagai batas pengendali.

\section{Pembahasan}

\subsection{Estimasi Parameter Distribusi Weibull}

Seperti yang sudah dijelaskan di awal bahwa parameter distribusi Weibull dapat diperoleh dengan memanfaatkan metode Maximum Likelihood sebagai berikut.

Berdasarkan persamaan (1) diatas dicari fungsi Likelihood yaitu

$$
\begin{aligned}
L & =L(\alpha, \beta)=\prod_{i=1}^{n} \alpha \beta x_{i}^{\beta-1} e^{-\alpha x_{i}^{\beta}} \\
& =(\alpha \beta)^{n} \prod_{i=1}^{n} x_{i}^{\beta-1} e^{-\sum_{i=1}^{n} \alpha x_{i}^{\beta}}
\end{aligned}
$$

Berdasarkan persamaan (2) dicari logaritma natural dan diperoleh

$$
\ln L=n \ln (\alpha \beta)+(\beta-1) \sum_{i=1}^{n} \ln x_{i}-\sum_{i=1}^{n} \alpha x_{i}{ }^{\beta}
$$

Dengan mencari derivatif parsial persamaan (3) terhadap $\alpha$ dan $\beta$ dengan nilai kedua derivatif tersebut adalah nol dan diselesaikan maka akan diperoleh 


$$
\alpha=\frac{n}{\sum_{i=1}^{n} x_{i}^{\beta}}
$$

Nilai pada persamaan (4) disubstitusikan ke dalam hasil derivative parsial terhadap $\beta$ dan diperoleh hasil

$$
\frac{\sum_{i=1}^{n} x_{i}^{\beta} \ln x_{i}}{\sum_{i=1}^{n} x_{i}{ }^{\beta}}-\frac{1}{\beta}=\frac{\sum_{i=1}^{n} \ln x_{i}}{n}
$$

Untuk $\beta>0$, hasil erivative parsial di atas tidak dapat diselesaikan. Namun untuk memperoleh parameter $\alpha$ dan $\beta$ digunakan metode Newton-Raphson. Untuk itu proses selanjutnya adalah dengan mencari erivative parsial kedua dari $\ln L$ dan akan diperoleh rumus iterasi untuk metode Newton-Raphson adalah sebagai berikut.

$$
\begin{gathered}
\beta_{k+1}=\beta_{k}+\frac{f\left(\beta_{k}\right)}{f^{\prime}\left(\beta_{k}\right)} \\
\beta_{k+1}=\beta_{k}+\frac{\frac{\sum_{i=1}^{n} \ln x_{i}}{n}+\frac{1}{\beta_{k}}-\frac{\sum_{i=1}^{n} x_{i}^{\beta_{k}} \ln x_{i}}{\sum_{i=1}^{n} x_{i}^{\beta_{k}}}}{\frac{1}{\beta_{k}{ }^{2}}+\frac{\left[\sum_{i=1}^{n} x_{i}^{\beta_{k}}\left(\ln x_{i}\right)^{2} \sum_{i=1}^{n} x_{i} \beta_{k}\right]-\left(\sum_{i=1}^{n} x_{i}^{\beta_{k}} \ln x_{i}\right)^{2}}{\left(\sum_{i=1}^{n} x_{i}^{\beta_{k}}\right)^{2}}}
\end{gathered}
$$

Berdasarkan penelitian dari Thoman, Bain dan Antle (1969) maka titik awal dari iterasi adalah

$$
\hat{\beta}_{0}=\left\{\frac{\frac{6}{\pi^{2}}\left[\sum_{i=1}^{n}\left(\ln x_{i}\right)^{2}-\frac{\left(\sum_{i=1}^{n} \ln x_{i}\right)^{2}}{n}\right]}{n-1}\right\}^{-\frac{1}{2}}
$$

Dengan pendekatan ini, metode Newton-Raphson hanya memerlukan rata-rata 3,5 iterasi Newton untuk mencapai tingkat ketelitian sampai $10^{-4}$ [2]. Untuk mengaplikasikan metode maksimum likelihood dalam mencari parameter distribusi Weibull akan digunakan software Minitab.

\subsection{Batas Pengendali dengan Distribusi Weibull}

Untuk membentuk grafik pengendali dengan distribusi Weibull maka perlu dicari batas pengendali terlebih dahulu. Seperti telah dijelaskan pada pendahuluan bahwa batas pengendali diperoleh dengan memanfaatkan kuantil. Oleh karena itu perlu untuk mencari kuantil dari Distribusi Weibull sebagai berikut.

Berdasarkan persamaan (1) maka diperoleh fungsi distribusi kumulatif yaitu

$$
F(x)=1-e^{-a x^{b}}
$$

Kuantil yang diperoleh dengan mencari invers persamaan (9) sehingga diperoleh

$$
x=\frac{1}{\alpha}\{-\ln [1-F(x)]\}^{\frac{1}{\beta}}
$$

Pada distribusi normal atau dalam grafik pengendali Shewhart, $\mu-3 \sigma$ digunakan sebagai Batas Pengendali Bawah, $\mu$ sebagai Garis Tengah dan Batas Pengendali Atas yaitu $\mu+3 \sigma$. Untuk distribusi tidak normal seperti distribusi Weibull memanfaatkan kuantil bawah yaitu 0,00135 untuk membentuk Batas Pengendali Bawah (BPB), Garis Tengah (GT) adalah median dari data yaitu 0,5 yang menggantikan rata-rata. Untuk membentuk Batas Pengendali Atas (BPA) 
digunakan kuantil atas yaitu 0,99865 [3]. Oleh karena itu berdasarkan persamaan (10) di atas diperoleh

$$
\begin{aligned}
\mathrm{BPB} & =\frac{1}{\alpha}\{-\ln [1-0,00135]\}^{\frac{1}{\beta}} \\
\mathrm{GT} & =\frac{1}{\alpha}\{-\ln [1-0,5]\}^{\frac{1}{\beta}} \\
\mathrm{BPA} & =\frac{1}{\alpha}\{-\ln [1-0,99865]\}^{\frac{1}{\beta}}
\end{aligned}
$$

\subsection{Perbandingan Kemampuan Proses}

Untuk melihat aktivitas pengembangan sebelum produksi, untuk kuantifikasi variabilitas proses, analisis variabilitas relatif terhadap persyaratan atau spesifikasi produk dan untuk membantu pengembangan dan produksi dalam menghilangkan atau mengurangi banyaknya variabilitas maka salah satu cara yang dapat digunakan adalah dengan melihat Perbandingan Kemampuan Proses (PKP). PKP diperoleh dengan memanfaatkan Fungsi Distribusi Kumulatif yang diperkenalkan oleh Wierda pada tahun 1933 dalam paper A Multivariate Process Capability Index. Hasil PKP yang diperoleh dengan metode ini paling baik diantara metode lainnya seperti metode Burr dan metode Clements [3]. Formula PKP tersebut adalah sebagai berikut.

$$
P K P=\frac{\Phi^{-1}\left(0,5+0,5 \int_{B S B}^{B S A} f(x) d x\right)}{3}
$$

dimana $f(x)$ menunjukkan fungsi densitas dari proses.

\subsection{Gafik Pengendali dan Perbandingan Kemampuan Proses}

\subsubsection{Grafik Pengendali Individual Dengan Distribusi Weibull}

Grafik Pengendali dibentuk dengan membangkitkan 200 sampel random yang berdistribusi Weibull dengan parameter skala $(\alpha)$ yaitu 0,5 dan parameter bentuk ( $\beta)$ yaitu 2. Sampel tersebut kemudian dianalisis dengan grafik pengendali individual berdasarkan distribusi Weibull. Selanjutnya, sebelum mencari Batas Pengendali untuk Grafik Pengendali Distribusi Weibull, terlebih dahulu dianalisis apakah data yang dibangkitkan memiliki nilai parameter yang sesuai dengan parameteryang ditetapkan. Proses analisis menggunakan software Minitab dengan hasil sebagai berikut

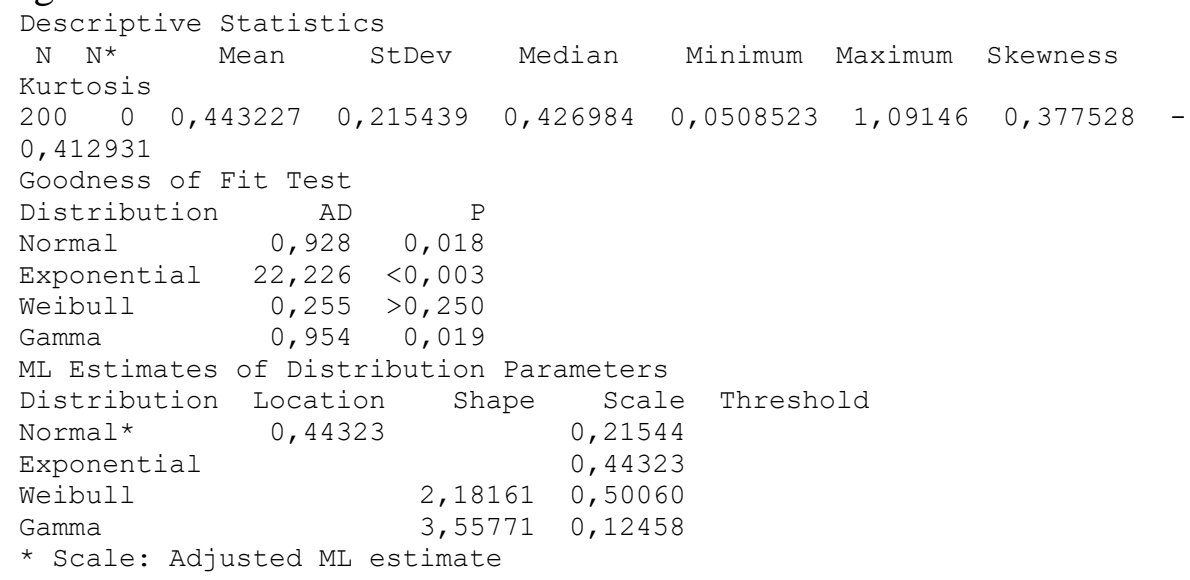


Berdasarkan hasil Goodness of Fit Test di atas terlihat bahwa data tersebut adalah data berdistribusi Weibull dengan P-Value $>0,250$ dan $\beta=2,18161$ serta $\alpha=$ 0,50060 . Nilai $\alpha$ dan $\beta$ inilah yang digunakan untuk membentuk Batas Pengendali berdasarkan persamaan (11), (12), dan (13) sehingga diperoleh $\mathrm{BPB}=0,024223$, $\mathrm{GT}=0,423184$ dan $\mathrm{BPA}=1,189547$

Berdasarkan Batas Pengendali di atas maka Grafik Pengendali yang dihasilkan yaitu:

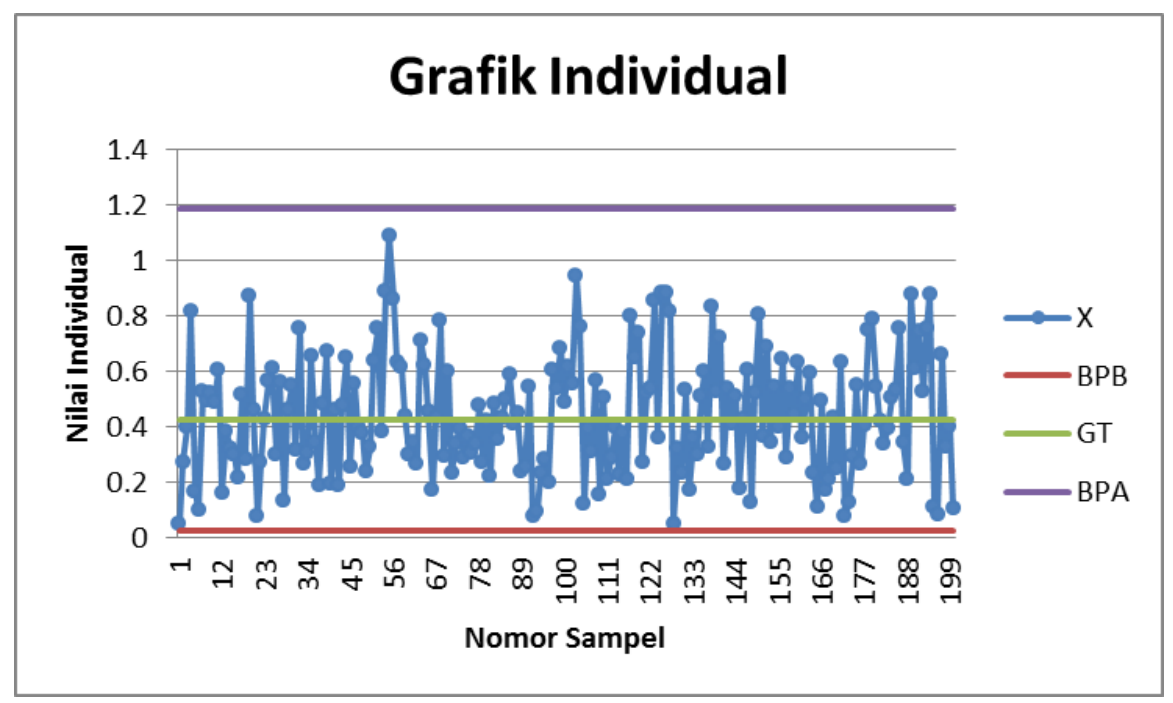

Gambar 1. Grafik Individual dengan Ms.Excel

Untuk membandingkannya dengan Grafik Pengendali Shewhart maka dibentuk Grafik Pengendali dengan Minitab sebagai berikut

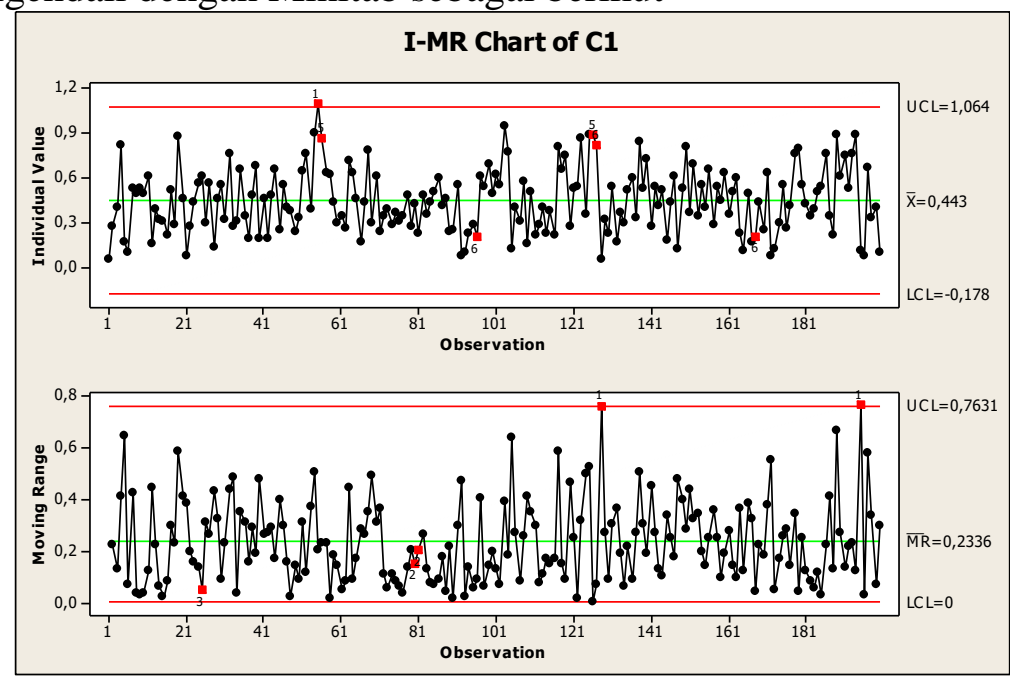

Gambar 2. Grafik Individual dengan MINITAB

Jika dibandingkan dua grafik di atas maka terlihat bahwa jika data dianalisis dengan distribusi Weibull maka grafik tampak terkendali. Hal ini terlihat dari tidak ada titik yang berada diluar batas pengendali. Namun, jika data dianalisis dengan Grafik Individual menggunakan Shewart, grafik tampak tak terkendali. 
Hal ini disebabkan karena data yang digunakan adalah data yang berdistribusi Weibull dan parameter yang digunakan juga tidak mendekati distribusi normal. Jadi, Jika data tidak berdistribusi normal dianalisis dengan grafik pengendali Shewhart diperoleh kesimpulan yang menyesatkan.

\subsubsection{Perbandingan Kemampuan Proses dengan Distribusi Weibull}

PKP diperoleh dengan memanfaatkan persamaan (14) yaitu jika digunakan target BSB dan BSA yaitu $[0,02,1,2]$, maka

$$
\int_{B S B}^{B S A} f(x) d x=\int_{0,02}^{1,2} \alpha \beta x^{\beta-1} e^{-\alpha x^{\beta}} d x
$$

Dengan memisalkan $u=\alpha x^{\beta}$ akan diperoleh

$$
\begin{aligned}
\int_{B S B}^{B S A} f(x) d x & \left.=-e^{-\alpha x^{\beta}}\right]_{0,02}^{1,2} \\
& =-e^{-\alpha 1,3^{\beta}}+e^{-\alpha 0,02^{\beta}}
\end{aligned}
$$

Sehingga PKP yang dihasilkan adalah

$$
\begin{aligned}
P K P & =\frac{\Phi^{-1}(0,5+0,5 \cdot 0,9990)}{3} \\
& =1,02
\end{aligned}
$$

Jika digambarkan dengan MINITAB maka akan diperoleh grafik kemampuan proses sebagai berikut

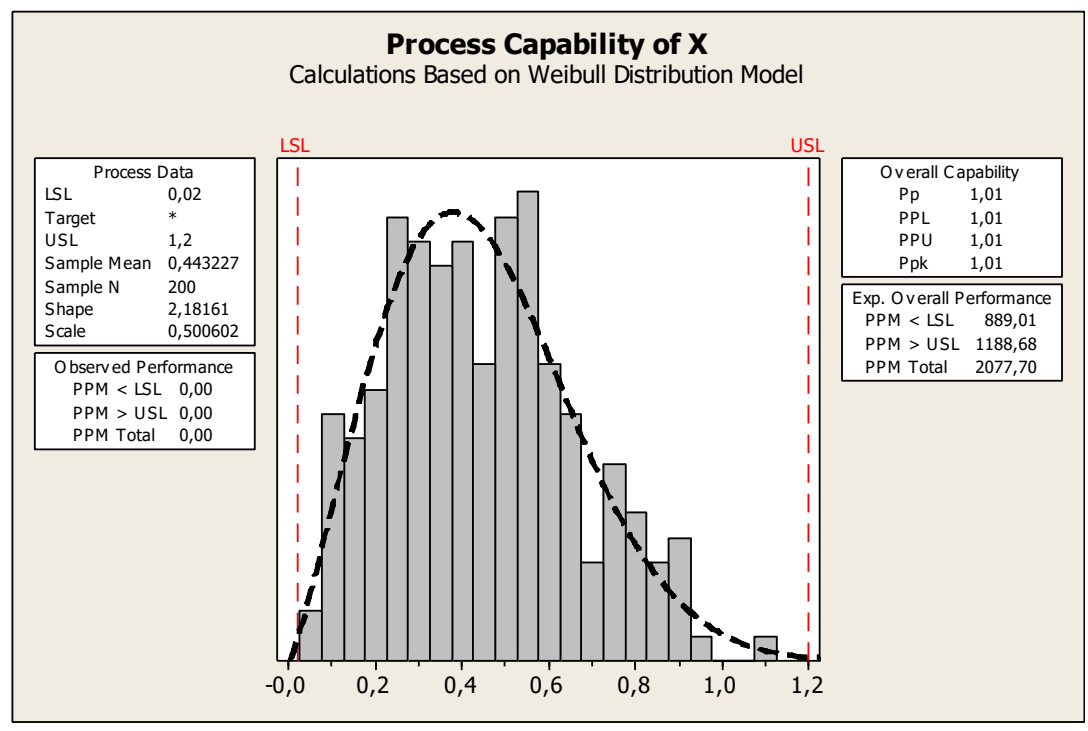

Gambar 3. Analisis Kemampuan Proses dengan MINITAB

Berdasarkan grafik hasil analisis kemampuan proses di atas terlihat bahwa nilai PKP yang dihasilkan adalah 1,01 sama dengan PKP yang dihasilkan jika digunakan target BSB dan BSA yaitu $[0,02,1,2]$. Hasil PKP yang diperoleh ini menunjukkan bahwa jika digunakan BSA dan BSB pada rentang $[0,02,1,2]$, 
maka hanya akan ada sedikit produk yang tak sesuai yang dihasilkan dari proses ini.

\section{Kesimpulan}

Beberapa hal yang dapat disimpulkan berdasarkan pembahasan di atas yaitu

1. Estimasi parameter dengan metode MLE terlihat telah memberikan hasil yang cukup akurat namun perlu dibandingkan dengan metode lainnya seperti Metode Bayes sehingga diperoleh metode yang manakah yang lebih baik dalam mengestimasi parameter distribusi Weibull.

2. Tidak semua data dapat dianalisis dengan Grafik Pengendali Shewhart (Grafik pengendali dengan asumsi bahwa data berdistribusi Normal). Jika data berdistibusi lain seperti distirbusi Weibull dianalisis dengan grafik pengendali Shewhart maka akan menghasilkan kesimpulan yang menyesatkan.

\section{Ucapan Terimakasih}

Diucapkan terimakasih kepada segala pihak yang terlibat sehingga penelitian ini dapat terselesaikan dengan baik.

\section{Daftar Pustaka}

[1] Samanta, B., Bhattacherjee, A, Problem Of Non-normality In Statistical Quality Control: A Case Study In A Surface Mine. The Journal of The South African Institute of Mining and Metallugry, 257-264, 2004.

[2] Zhang, M, Performance of Control Charts For Weibull Processes. Electronic Theses, Treatises and Dissertations (ETDs) 537,1-59, 2008.

[3] Ahmad,S., Abdollahian, S., Zeephongsekul, P., dan Abbasi, B, Performance Analysis For Skewed Data.

http://www.ubicc.org/files/pdf/UBICC_IKE07_Performance\%20Analysis\%2 Ofor\%20skewed\%20data_191_191.pdf diakses tanggal 17 Maret 2018. 
